\section{Gold(0) Porphyrins on Gold Nanoparticles **}

\author{
Masayuki Kanehara, Hirokazu Takahashi and \\ Toshiharu Teranishi ${ }^{*}$
}

Gold $(\mathrm{Au})$ nanoparticles play important roles in different branches of science, such as in nanoelectronics, nonlinear optics, biological labeling, oxidation catalysis, etc. ${ }^{[1-5]}$ Many ligand-functionalized metal nanoparticles have been reported based on ligation using the chemical affinity of organic functional groups toward the nanoparticle surface in order to stabilize the nanoparticles. Polymers, ${ }^{[6]}$ linear molecules with long alkyl chains ${ }^{[7]}$ and dendrimers ${ }^{[8]}$ have all been effectively used for this purpose, relying on the $\sigma$-electrons of the functional groups. For the application of nanoparticles in nanoelectronic devices, exploiting the organoelectronic $\pi$-orbital interactions, which are generally used in electron-conductive polymers and organic transistors etc., are quite important in light of the reduction of the tunneling resistance of the surrounding ligands. Porphyrin is one of the most important $\pi$ conjugated compound and recent study of porphyrin on $\mathrm{Au}(111)^{[9]}$ encouraged us to investigate the interaction between $\mathrm{Au}$ nanoparticle and porphyrin $\pi$-conjugated system. In this communication, we report the preparation, structural analysis and unique optical properties of novel porphyrin speices on $\mathrm{Au}$ nanoparticles. The nitrogen atoms of porphyrin rings were found to have coordination ability to the Au nanoparticle surface, and the Soret-band intensity could be tuned by changing the distance between the porphyrin rings and the Au nanoparticle surface.

To obtain stable Au nanoparticles surrounded by $\pi$-orbitals perpendicular to the Au surface, we focused on Au nanoparticles formed through strong multidentate ligation using thiol-derivatives. As shown in Figure 1, multidentate macrocyclic porphyrin-thioester derivatives, tetrakis-5,10,15,20-(2-acetylthio-phenyl)porphyrin $\left(\mathrm{SC}_{0} \mathrm{P}\right)$ and tetrakis-5,10,15,20-(2-acetylthio-methylphenyl) porphyrin $\left(\mathrm{SC}_{1} \mathrm{P}\right)$ were synthesized. The $\mathrm{SC}_{1} \mathrm{P}$ ligand was designed with methylene groups inserted between the benzene rings and the acetylthio groups, in order to increase the distance between the porphyrin ring and the Au surface. The $\mathrm{SC}_{n} \mathrm{P}(n=0,1)$ ligands were synthesized from the corresponding aldehyde and pyrrole using Lindsey's method ${ }^{[10]}$ in $15 \%$ and $40 \%$ yields, respectively. ${ }^{[11]}$ Since the acetylthio groups easily dissociate to form sulfur-Au bonds on

[*] Dr. M. Kanehara, H. Takahashi and Prof. T. Teranishi Graduate School of Pure and Applied Sciences University of Tsukuba

1-1-1 Tennodai, Tsukuba, Ibaraki 305-8571, Japan Fax: (+81)29-853-6503

E-mail: teranisi@chem.tsukuba.ac.jp

[**] We thank Dr. Nakayama and Dr. Shingaya for Laser Raman measurements, and Prof. Sugimura for XPS measurements. The present work was supported by a Grant-in-Aid for Scientific Research (A) (No. 19205016) and Scientific Research on Priority Area "Chemistry of Coordination Space" (No. 18033007) from MEXT, Japan and Industrial Technology Research Grant Program in '04 from NEDO of Japan (T.T.).

Supporting information for this article is available on the WWW under http://www.angewandte.org or from the author.

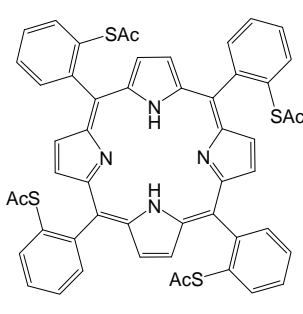

$\mathrm{SC}_{0} \mathrm{P}$

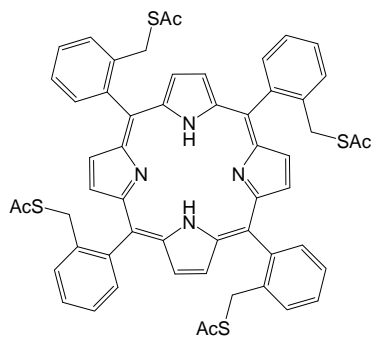

$\mathrm{SC}_{1} \mathrm{P}$ bare Au surfaces in a slightly alkaline condition, ${ }^{[12]}$ these groups are considered an excellent thiol source to protect the Au surface. The $\mathrm{SC}_{n} \mathrm{P}$-protected $\mathrm{Au}\left(\mathrm{SC}_{n} \mathrm{P}-\mathrm{Au}\right)$ nanoparticles were prepared by ligand exchange reactions from citrate-protected $\mathrm{Au}$ (CA-Au) nanoparticles. After ligand exchange, the nanoparticles became insoluble in water but soluble in $N, N$-dimethylacetamide (DMAc), indicating that ligand exchange was accomplished. Further evidence was confirmed from XPS measurements, that is, the C1s peaks assigned to the carbonyl carbon of both citrate and acetylthio groups of $\mathrm{SC}_{n} \mathrm{P}$ ligands disappeared (Figure $\mathrm{S} 1$ ), indicating that the citrate ligands were completely exchanged with the $\mathrm{SC}_{n} \mathrm{P}$ ligands and that the acetylthio groups dissociated to protect Au surface. In order to confirm the stability of $\mathrm{SC}_{n} \mathrm{P}$, these ligands were annealed with citrate and tannic acid in the absence of Au nanoparticles at $120^{\circ} \mathrm{C}$ in DMAc/water mixed solvent. No UV-Vis spectral change was observed, demonstrating that the $\mathrm{SC}_{n} \mathrm{P}$ ligands are stable in the ligand-exchange condition.

Figure 1 shows the TEM images of CA-Au and $\mathrm{SC}_{n} \mathrm{P}-\mathrm{Au}$ nanoparticles. The sizes of the $\mathrm{SC}_{n} \mathrm{P}-\mathrm{Au}$ nanoparticles remained unchanged after the ligand exchange. The DMAc solutions of $\mathrm{SC}_{n} \mathrm{P}$ $\mathrm{Au}$ nanoparticles are quite stable under ambient conditions, and no size change has been observed at least within one year due to the tetradentate nature of the $\mathrm{SC}_{n} \mathrm{P}$ ligands. In order to confirm the existence of $\mathrm{SC}_{n} \mathrm{P}$ on the $\mathrm{Au}$ surface and reveal the coordination geometry, Laser Raman measurements, thermogravimetric analysis (TGA) and XPS analysis were conducted. The Laser Raman spectra of the $\mathrm{SC}_{n} \mathrm{P}-\mathrm{Au}$ nanoparticles were similar to those of the $\mathrm{SC}_{n} \mathrm{P}$ ligands, indicating the existence of porphyrin rings on the $\mathrm{Au}$ nanoparticles (Figure S2). Further evidence was obtained by cyanide decomposition of $\mathrm{SC}_{n} \mathrm{P}-\mathrm{Au}$ nanoparticles. ${ }^{[13]}$ When the $\mathrm{SC}_{n} \mathrm{P}-\mathrm{Au}$ nanoparticles were treated with an excess amount of sodium cyanide,

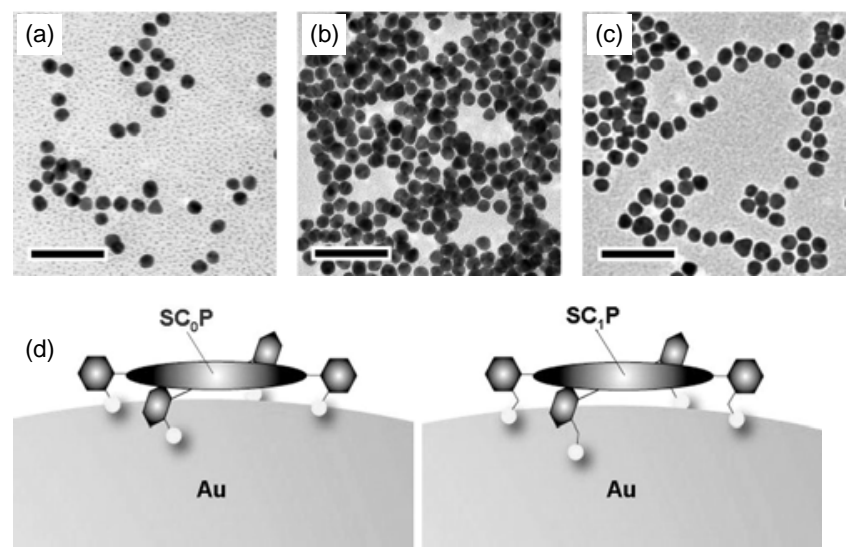

Figure 1. TEM images of (a) citrate- (b) $\mathrm{SC}_{0} \mathrm{P}$ - and (c) $\mathrm{SC}_{1} \mathrm{P}$ protected Au nanoparticles. Particle diameters are (a) $10.5 \pm 1.0 \mathrm{~nm}$, (b) $10.5 \pm 1.0 \mathrm{~nm}$ and (c) $10.0 \pm 0.9 \mathrm{~nm}$, respectively. Scale bar indicates $50 \mathrm{~nm}$. (d) Schematic illustrations of the coordination of $\mathrm{SC}_{n} \mathrm{P}$ ligands on the Au surface. 

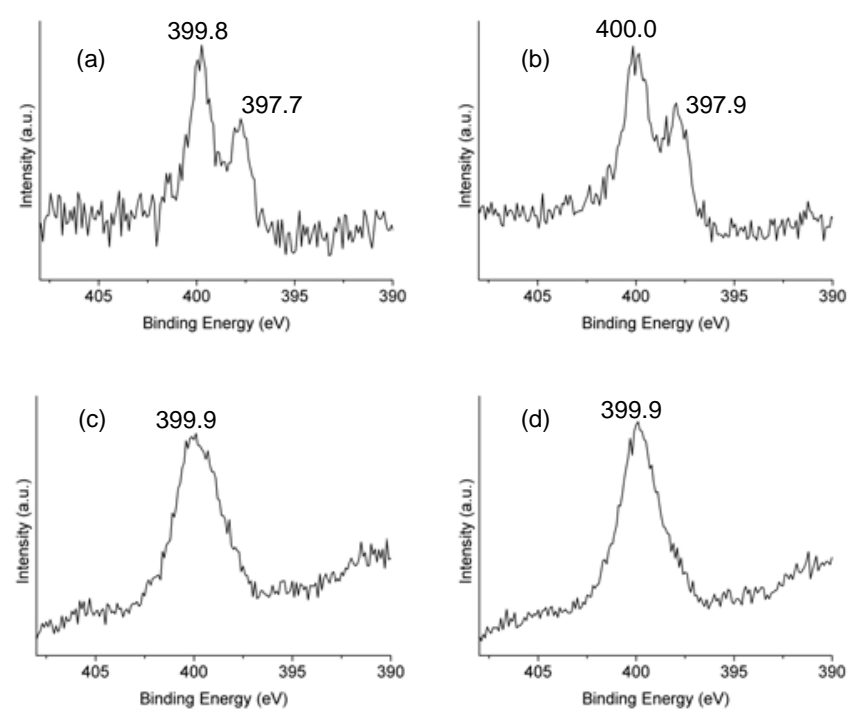

Figure 2. N1s core level XPS spectra for (a) $\mathrm{SC}_{0} \mathrm{P}$, (b) $\mathrm{SC}_{1} \mathrm{P}$, (c) $\mathrm{SC}_{0} \mathrm{P}-\mathrm{Au}$ and (d) $\mathrm{SC}_{1} \mathrm{P}-\mathrm{Au}$

the intensities of both the Soret-band and Q-band were recovered regardless of the decomposition of the $\mathrm{SC}_{n} \mathrm{P}$ ligands (Figure S3). TGA analysis revealed the weight losses of $3.1 \%$ and $3.0 \%$ for $\mathrm{SC}_{0} \mathrm{P}-\mathrm{Au}$ and $\mathrm{SC}_{1} \mathrm{P}-\mathrm{Au}$, corresponding to the number of ligands on a single $\mathrm{Au}$ nanoparticle to be 246 and 226 for $\mathrm{SC}_{0} \mathrm{P}-\mathrm{Au}$ and $\mathrm{SC}_{1} \mathrm{P}-$ $\mathrm{Au}$, respectively. Considering the length of the neighbouring mesosubstituted phenyl groups are about $1.25 \mathrm{~nm}, 222 \mathrm{SC}_{n} \mathrm{P}$ ligands can cover a single $\mathrm{Au}$ nanoparticle surface, suggesting that these porphyrin ligands densely protect the $\mathrm{Au}$ nanoparticles in a facecoordination fashion, as shown in Figure 1d. ${ }^{[11]}$

Further evidence for the face coordination of $\mathrm{SC}_{n} \mathrm{P}$ ligands on $\mathrm{Au}$ nanoparticles could be confirmed by XPS measurements. The $\mathrm{SC}_{n} \mathrm{P}$ ligands exhibit two distinct chemically-inequivalent N1s corelevel spectra corresponding to free iminic $(-\mathrm{C}=\mathrm{N}-)$ and pyrrolic ($\mathrm{NH}-$ ) nitrogens, from lower to higher binding energy, respectively (Figure 2). On the other hand, both $\mathrm{SC}_{n} \mathrm{P}$-Au nanoparticles exhibit a single N1s peak with a binding energy at $399.9 \mathrm{eV}$, which is similar to that of the iminic nitrogens coordinating to the $\mathrm{Au}(111)$ surface, as reported by Feringa and co-workers. ${ }^{[9]}$ They observed three distinct N1s peaks (free iminic, coordinating iminic and free pyrrolic) on $\mathrm{Au}(111)$ substrate, whereas $\mathrm{SC}_{n} \mathrm{P}-\mathrm{Au}$ nanoparticles exhibit a single N1s peak, indicating that the four nitrogen atoms of the $\mathrm{SC}_{n} \mathrm{P}$ ligands dehydrate to coordinate to the Au surface to form $\mathrm{Au}(0)$ porphyrins. Although the position of the peak with a binding energy at ca. $399.9 \mathrm{eV}$ corresponds to the binding energy of nitrogen atoms in metalloporphyrins, ${ }^{[9]}$ the possibility of the formation of $\mathrm{Au}(\mathrm{III})$ porphyrin was denied, because no $\mathrm{Au} 4 \mathrm{f}_{7 / 2}$ peak assigned to oxidized gold was observed in $\mathrm{SC}_{n} \mathrm{P}-\mathrm{Au}$ (Figure S4). We conclude this unique coordination fashion as a nanoparticle effect. The porphyrin derivatives are expected to coordinate mainly to the step edges and plane boundaries that the nanoparticles possess on their surfaces, centering at the porphyrin nitrogens. To the best of our knowledge, this coordination fashion that the porphyrin molecules were spontaneously dehydrated to coordinate on zero valent metal has never been reported not only for porphyrins on bulk $\mathrm{Au}(111)$ or $\mathrm{Ag}(111)$ surfaces but also for previously reported $\mathrm{Ru}(0)$ and $\mathrm{Fe}(0)$ porphyrins. Furthermore, the $\mathrm{Ru}(0)^{[14]}$ and $\mathrm{Fe}(0)^{[15]}$ porphyrins have quite high reactivity with both organic and inorganic electrophile, while our $\mathrm{SC}_{n} \mathrm{P}-\mathrm{Au}$ nanoparticles are extensively stable against various electrophile including water and DMAc, and no
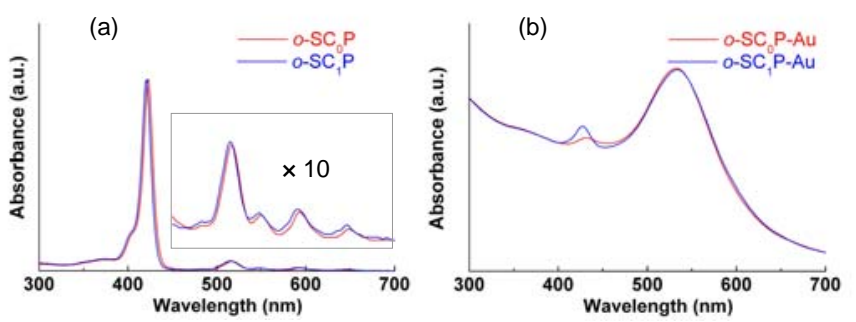

Figure 3. UV-Vis spectra of (a) $\mathrm{SC}_{n} \mathrm{P}$ ligands and (b) $\mathrm{SC}_{n} \mathrm{P}-\mathrm{Au}$ nanoparticles. Inset in (a) shows the Q-bands expanded by 10 . Each set of spectra was normalized by (a) ligand and (b) nanoparticle concentrations.

decomposition of $\mathrm{SC}_{n} \mathrm{P}$ ligands on $\mathrm{Au}$ nanoparticles was observed by UV-Vis spectra under ambient condition. The ligand exchange condition was almost neutral and the UV-vis spectral changes are not observed for the $\mathrm{SC}_{n} \mathrm{P}$-Au nanoparticles after adding acetic acid to the $\mathrm{SC}_{n} \mathrm{P}-\mathrm{Au}$ nanoparticles solution. Thus, it was concluded that the deprotonation of the porphyrins was not induced by some bases. Presumably, the strong tetradentate coordination structure of $\mathrm{SC}_{n} \mathrm{P}$ ligands fixes the porphyrin rings on $\mathrm{Au}$ nanoparticle surfaces to stabilize the deprotonated porphyrin rings. In addition, refluxing the toluene solution containing Au nanoparticles, tetraphenylporphyrin, and dodecanethiol did not result in the $\mathrm{Au}(0)$ porphyrin formation.

Interestingly, these $\mathrm{SC}_{n} \mathrm{P}-\mathrm{Au}$ nanoparticles exhibited unique optical properties. Figure 3 shows the UV-Vis spectra of the DMAc solutions containing $\mathrm{SC}_{n} \mathrm{P}$ ligands or $\mathrm{SC}_{n} \mathrm{P}-\mathrm{Au}$ nanoparticles. The DMAc solutions of $\mathrm{SC}_{0} \mathrm{P}$ and $\mathrm{SC}_{1} \mathrm{P}$ gave Soret-bands at 421 and $423 \mathrm{~nm}$, respectively, and four distinct Q-bands in the range from $515 \mathrm{~nm}$ to $646 \mathrm{~nm}$. On coordinating $\mathrm{SC}_{n} \mathrm{P}$ ligands on $\mathrm{Au}$ nanoparticles, the Q-bands for $\mathrm{SC}_{n} \mathrm{P}-\mathrm{Au}$ nanoparticles completely disappeared and the Soret-bands for the $\mathrm{SC}_{0} \mathrm{P}-\mathrm{Au}$ and $\mathrm{SC}_{1} \mathrm{P}-\mathrm{Au}$ nanoparticles were broadened and red-shifted to 432 and $427 \mathrm{~nm}$, respectively. The molar absorption coefficients of the Soret-bands for the $\mathrm{SC}_{0} \mathrm{P}-\mathrm{Au}$ and $\mathrm{SC}_{1} \mathrm{P}-\mathrm{Au}$ nanoparticles were calculated to be $2.5 \times 10^{4}$ and $7.0 \times 10^{4} \mathrm{M}^{-1} \mathrm{~cm}^{-1}$, respectively, using TGA results and subtraction of the Au nanoparticle background. These values are smaller by one order of magnitude than those for $\mathrm{SC}_{n} \mathrm{P}$ ligands themselves, $\sim 3.9 \times 10^{5} \mathrm{M}^{-1} \mathrm{~cm}^{-1}$.

These results are completely different from those of the $\mathrm{Au}$ nanoparticles protected by meso-3-acetylthiophenyl-substituted $\operatorname{porphyrin}^{[16]}$ and other porphyrin derivatives, ${ }^{[17,18]}$ where the porphyrin rings are tilting at the $\mathrm{Au}$ surface and the extensive diminishing of both the Soret-band and Q-band were not observed. The drastic change in the absorbance of Soret-band and Q-band for porphyrin molecules on $\mathrm{Au}$ nanoparticles have to result from the change in electronic state of porphyrins. Generally, a red-shift of the Soret band results from the formation of a side-by-side partially $\pi-\pi$ stacked J-aggregate-like structure, ${ }^{[19]}$ although the formation of $\mathrm{J}$ aggregates cannot explain the decrease in intensity of the Soret-band and Q-band of the $\mathrm{SC}_{n} \mathrm{P}-\mathrm{Au}$ nanoparticles. Distortion of the porphyrin ring may lead to the decrease in the Soret-band intensity, although a large distortion of the porphyrin ring must accompany the considerable shift of the Soret-band. ${ }^{[20]}$ Thus, this distortion model is not applicable to our case, because only a few nanometer red-shifts are observed for the $\mathrm{SC}_{n} \mathrm{P}-\mathrm{Au}$ nanoparticles. Though the details are not understood yet, the unique optical change exhibited by the porphyrin rings may be derived from the direct interaction between the porphyrin $\pi$ and Au orbitals, in other words, the partial charge transfer between the porphyrin and Au, which is often observed between the porphyrin rings and fullerenes. ${ }^{[21]}$ Another 
possibility includes the hybridization of the porphyrin $\pi$ and Au orbitals to form new orbitals between the porphyrin rings and $\mathrm{Au}$ surfaces, as calculated for the conductive carbon nanotube on aluminum surface. ${ }^{[22]}$ Considering the longer porphyrin-Au distance for $\mathrm{SC}_{1} \mathrm{P}-\mathrm{Au}$, as illustrated in Figure $1 \mathrm{~d}$, the Au-porphyrin interaction for $\mathrm{SC}_{0} \mathrm{P}-\mathrm{Au}$ is expected to be much larger than that for $\mathrm{SC}_{1} \mathrm{P}-\mathrm{Au}$, resulting in the larger red-shift and the broadening of the Soret band for $\mathrm{SC}_{0} \mathrm{P}-\mathrm{Au}$.

In conclusion, we have synthesized macrocyclic porphyrin ligands $\left(\mathrm{SC}_{0} \mathrm{P}\right.$ and $\left.\mathrm{SC}_{1} \mathrm{P}\right)$ which protect $\mathrm{Au}$ nanoparticles with the porphyrin rings parallel to the Au surface. The porphyrin rings on $\mathrm{Au}$ nanoparticles have stronger coordination ability to Au surface than that to $\mathrm{Au}(111)$ substrate, since all iminic nitrogen atoms of $\mathrm{SC}_{n} \mathrm{P}$ ligands participate the ligation to the Au nanoparticle surface to form quite stable $\mathrm{Au}(0)$ porphyrins. The $\mathrm{Au}(0)$ porphyrin has a novel structure that the porphyrin molecule on the Au nanoparticle surface was dehydrated to coordinate to the surface $\mathrm{Au}$ atom and such coordination fashion is completely different from the conventional metalloporphyrins, which coordinate to the isolated metal ions. The $\mathrm{SC}_{n} \mathrm{P}$-Au nanoparticles show a ligand-dependent decrease of the Soret-band intensity, where the shift and decrease of the Soret-band for $\mathrm{SC}_{0} \mathrm{P}-\mathrm{Au}$ are larger than those for $\mathrm{SC}_{1} \mathrm{P}-\mathrm{Au}$. The extinction of the Soret-band, which is tuned by the coordination distance between the porphyrin ring and the Au surface, implies an electronic interaction between the porphyrin and Au nanoparticle. A first principle calculation approach to confirm our claim is currently in progress.

\section{Experimental Section}

\section{Preparation of $\mathrm{SC}_{n} \mathrm{P}$-Au nanoparticles.}

Citrate-capped $\mathrm{Au}(\mathrm{CA}-\mathrm{Au})$ nanoparticles with the size of $10.5 \pm 1.0$ $\mathrm{nm}$ were prepared according to the literature. ${ }^{[23]}$ The CA-Au aqueous solution was poured into the same volume of the $\mathrm{SC}_{n} \mathrm{P} N, N$ dimethylacetamide (DMAc) solution, where $1 / 2$ equivalent of ligand to surface Au atoms was used based on the spherical model. ${ }^{[24]}$ Because the $\mathrm{SC}_{n} \mathrm{P}$ ligands have four atropisomers at room temperature, ${ }^{[25]}$ the DMAc solution of the nanoparticles was annealed at $120{ }^{\circ} \mathrm{C}$ to promote the coordination of four thiolate groups onto the same nanoparticle surface. After removing the solvent under reduced pressure, water was added and the resulting precipitate was filtered and washed with water, methanol and toluene to obtain pure $\mathrm{SC}_{n} \mathrm{P}-\mathrm{Au}$ nanoparticles. Purification was checked by analytical gel permeation chromatography.

Received: ((will be filled in by the editorial staff))

Published online on ((will be filled in by the editorial staff))

Keywords: porphyrin · Au nanoparticle · metalloporphyrin · Soretband · electronic interaction

M.-C. Daniel, D. Astruc, Chem. Rev. 2004, 104, 293.

[2] M. Kanehara, Y. Oumi, T. Sano, T. Teranishi, J. Am. Chem. Soc. 2003, 125, 8708.
[3] Y. Azuma, M. Kanehara, T. Teranishi, Y. Majima, Phys. Rev. Lett. 2006, 98, 016108.

[4] M. Kanehara, E. Kodzuka, T. Teranishi, J. Am. Chem. Soc. 2006, 128, 13084.

[5] D. Astruc, F. Lu, J. R. Aranzaes, Angew. Chem. 2005, 117, 8062; Angew. Chem. Int. Ed. 2005, 44, 7852.

[6] T. Teranishi, I. Kiyokawa, M. Miyake, Adv. Mater. 1998, 10, 596.

[7] M. Brust, M. Walker, D. Bethell, D. J. Schiffrin, R. Whyman, Chem. Commun. 1994, 801.

[8] J. Zheng, J. T. Petty, R. M. Dickson, J. Am. Chem. Soc. 2003, 125, 7780.

[9] N. Katsonis, J. Vicario, T. Kudernac, J. Visser, M. M. Pollard, B. L. Feringa, J. Am. Chem. Soc. 2006, 128, 15537.

[10] D. T. Gryko, C. Clausen, K. M. Roth, N. Dontha, D. F. Bocian, W. G. Kuhr, J. S. Lindsey, J. Org. Chem. 2000, 65, 7345.

[11] See Supporting Information.

[12] A. A. Yasseri, D. Syomin, V. L. Malinovskii, R. S. Loewe, J. S. Lindsey, F. Zaera, D. F. Bocian, J. Am. Chem. Soc. 2004 126, 11944

[13] K. R. Gopidas, J. K. Whitesell, M. A. Fox, J. Am. Chem. Soc. 2003, 125, 6491.

[14] J. P. Collman, P. J. Brothers, L. McElwee-White, E. Rose, J. Am. Chem. Soc. 1985, 107, 6110.

[15] T. Mashiko, C. A. Reed, K. J. Haller, W. R. Scheidt, Inorg. Chem. 1984, 23, 3192.

[16] M. Kanehara, T. Teranishi, e-J. Surf. Sci. Nanotech. 2005, $3,30$.

[17] I. loufova-Srnova, B. Vlkova, Nano Lett. 2002, 2, 121.

[18] H. Imahori, Y. Kashiwagi, Y. Endo, T. Hanada, Y. Nishimura, I. Yamazaki, Y. Araki, O. Ito, S. Fukuzumi, Langmuir 2004, 20, 73.

[19] H. Imahori, H. Norieda, Y. Nishimura, I. Yamazaki, K. Higuchi, N. Kato, T. Motohiro, H. Yamada, K. Tamaki, M. Arimura, Y. Sakata, J. Phys. Chem. B 2000, 104, 1253.

[20] J. P. Hill, I. J. Hewitt, C. E. Anson, A. K. Powell, A. L. McCarty, P. A. Karr, M. E. Zandler, F. D'Souza, J. Org. Chem. 2004, 69, 5861.

[21] A. Hosseini, S. Taylor, G. Accorsi, N. Armaroli, C. A. Reed, P. D. W. Boyd, J. Am. Chem. Soc. 2006, 128, 15903.

[22] S. Okada, A. Oshiyama, Phys. Rev. Lett. 2005, 95, 206804.

[23] J. W. Slot, H. J. Geuze, Eur. J. Cell Biol. 1985, 38, 87.

[24] R. H. Terrill, T. A. Postlethwaite, C.-h. Chen, C.-D. Poon, A. Terzis, A. Chen, J. E. Hutchison, M. R. Clark, G. Wignall, J. D. Londono, R. Superfine, M. Falvo, C. S. J. Jr., E. T. Samulski, R. W. Murray, J. Am. Chem. Soc. 1995, 117, 12537.

[25] Y. Kuroda, T. Hiroshige, T. Sera, Y. Shiroiwa, H. Tanaka, H. Ogoshi, J. Am. Chem. Soc. 1989, 111, 1912. 
Gold(0) Porphyrins on Gold

Nanoparticles

Masayuki Kanehara, Hirokazu

Takahashi and Toshiharu Teranishi

Gold(0) Porphyrins on Gold

Nanoparticles

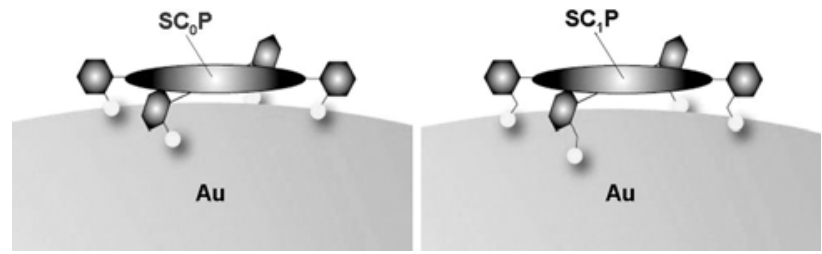

Multidentate macrocyclic porphyrin-thioester derivatives densely protect the Au nanoparticles in a face-coordination fashion to form quite stable $\mathrm{Au}(0)$ porphyrins. The decrease in the Soret-band intensity can be tuned by the distance between the porphyrin ring and the Au surface. 